\title{
Individual Analysts' Earnings Forecasts: Evidence For Overreaction In The UK Stock Market
}

Dimitris F. Kenourgios, Athens University of Economics and Business, Greece Nikolaos Pavlidis, Brunel University, UK

\begin{abstract}
This paper presents an analysis of two forms of overreaction (generalized overreaction and overreaction to prior earnings changes) in analysts' earnings forecasts for the UK stock market, using a sample of individual forecasts of earning per share from a British investment bank over the period 1989-2002. Given that previous UK empirical research over 1980s and mid '90s has provided limited and contradictory findings, we investigate whether and how overreaction of analysts forecasts varies across forecast horizons, firm size (small and large) and growth opportunities (high and low P/E ratio) in order to provide further and comparable evidence. Overall, our findings support the generalized overreaction hypothesis but reject the firm size effect, the overreaction for high $P / E$ ratio companies and the higher overreaction regarding the forecasting horizon. Keywords: Overreaction, Underreaction, Analysts forecasts, forecast horizons, size effect, pricelearnings ratio.
\end{abstract}

\section{Introduction}

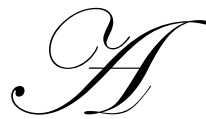

classical analysis of financial analysts views them as rational market experts who immediately and without bias incorporate information into their earnings forecasts and make trade recommendations. This view presumes analysts' forecasted earnings immediately and unbiasedly incorporate all new information. However, most of the research on financial analysts' behaviour documents a systematic misinterpretation to earnings information. Some studies conclude that analysts systematically overreact to new information, while more recent studies provide evidence of systematic underreaction. These results appear to be inconsistent with each other and consistent with inefficient (irrational or suboptimal) forecasts.

The purpose of this study is to examine earnings forecasts generated by individual analysts employed within a large UK investment bank, for evidence of overreaction. Specifically, two forms of overreaction are studied at various forecast horizons: (1) generalised overreaction, where changes in forecasted earnings are overly extreme; and (2) overreaction to prior changes in earnings. Analysts' overreaction in UK stock market is tested by employing two basic methodologies: (1) DeBondt and Thaler's (1990) methodology of generalised overreaction; and (2) Abarbanell and Bernard's (1992) methodology of underreaction/overreaction to past earnings. Despite the passage of time and several methodological refinements, the bulk of research in this issue has been employed the above two models using US, UK or other market's data.

Furthermore, we provide further evidence by including two main modifications to our testing procedure. First, we test both models relative to the size of the firms included in our sample, in order to examine the effect of firm size on overreaction/underreaction. Second, we investigate whether analysts' reaction differs regarding growth opportunities of companies (high and low P/E ratios).

Our research is motivated by two factors. First, further investigation of analysts' reaction to earnings information is driven by the limited UK evidence compared with the empirical applications in USA. Our results would also help to extend the extensive US based evidence to UK and to provide additional evidence to the research 
on financial analysts. Second, given that the literature does not lean cleanly toward either overreaction or underreaction, it is interesting to compare our findings over an extensive and more recent period covered three decades (1989-2002) with evidence provided by the main UK studies during 1980's and mid '90s.

We present evidence that is consistent with the overreaction hypothesis. Specifically, our evidence supports the generalised overreaction and rejects overreaction/underreaction to prior performance. However, our results do not support either the overreaction due to small firm size or the prior expectation about the overreaction for high $\mathrm{P} / \mathrm{E}$ ratio companies and the higher overreaction regarding the forecasting horizon.

The rest of the paper is structured as follows. Section 2 comprises a literature review that provides the background for this study. In Section 3 we describe the data and the methodology used. In Section 4 we present the empirical results. Concluding remarks and possible explanations of our findings are set out in Section 5.

\section{Literature Review}

\subsection{US Evidence of Stock Price Overreaction}

In their seminal work, DeBondt and Thaler (D\&T) (1985) provide evidence of performance reversal observing that a portfolio of NYSE stocks which perform worst (best) over an initial 3-year period (rank or portfolio formation period) tend to perform best (worst) in the subsequent 3-year period (test period). This 'winner-loser' effect is interpreted as investors' irrational behaviour suggesting that they overreact, that excessive optimism or pessimism causes prices to be driven too high or too low from their fundamental values, and that overreaction is corrected in a subsequent period. In forming expectations, investors give too much weight to the past performance of firms and too little to the fact that performance tends to mean-revert. They also suggest that the fact an investor can earn abnormal profit by buying past losers and selling past winners short (a contrarian investment strategy using past prices as the information set) has important implications for the validity of efficient market hypothesis (EMH).

Later studies of D\&T also provide evidence of overreaction hypothesis. D\&T (1987) describe how investor 'myopia' could lead to an overemphasis on earnings from the recent past. They also suggest that stock market participants may overreact to current earnings, not recognising in the future. D\&T (1990) conduct tests on US analysts' one-year-ahead and two-years-ahead earnings forecasts. Their results indicate that predicted earnings changes are greater than actual earnings changes, implying that market professionals overreact to changes in earnings figures. Moreover, the extent of overreaction in analysts' earnings forecasts increases with the length of the forecast horizon, because overreaction increases with uncertainty and the uncertainty is greater over longer horizons.

The overreaction hypothesis proposed and supported by D\&T has generated much interest in subsequent years. Specific studies question the strong finding of D\&T of a stock market overreaction on grounds of varying betas, size differences between winner and loser stocks and bid-ask spread bias ${ }^{1}$. Chan (1988) rejects the overreaction hypothesis by arguing that D\&T fail to control for time-varying risk, and when properly controlled the hypothesis disappears. Specifically, he argues that stocks with a series of negative abnormal returns will experience an increase in their equity betas, and thus increase their expected returns. This is because equity beta is a function of gearing. Likewise, the 'winner' stocks which experience a series of positive abnormal returns have reduced betas and lower expected returns. Ball and Kothari (1989) make a similar claim.

Zarowin (1990) claims that firm size can explain this overreaction (firm size effect). He argues that losers tend to be smaller than winners and when size is controlled there is no significant difference in test period performance. He also analyses the periods when losers are smaller than winners, and periods when winners are smaller than losers. The results indicate that when losers are smaller, they outperform the winners. When winners are smaller, they outperform the losers. Therefore, Zarowin concludes that losers' superior performance over winners during the 3-year test period is due, not to overreaction, but to size discrepancies. 
Other criticisms of overreaction studies include the impact of bid-ask spread bias (Kaul and Nimalendran, 1990; Conrad and Kaul, 1993). This is a particular problem with small firms or low-priced stocks which have proportionally bigger bid-ask spreads and high chances of non-trading; bid-ask spread may induce spurious autocorrelation.

However, the above critiques of overreaction have not gone unchallenged. D\&T (1987) and Chopra et. al. (1992) reject the explanation that the "winner-loser effect" is explained by changes in beta. They argue that differential risk between winner and loser portfolios are insufficient to explain the excess returns identified in their study. Chopra et. al. (1992) provide evidence which is consistent with the overreaction hypothesis, and they reject Zarowin's explanations based on size effect as do Albert and Henderson (1995). Conrad and Kaul's arguments have been challenged by Loughran and Ritter (1996), in relation both to the impact of the return metric and the suggestion that low-priced stocks drive overreaction effects. Their general conclusion is that the findings of Conrad and Kaul may have been overstated.

\subsection{UK and other Single Country Studies Suggesting Overreaction.}

Studies investigating the overreaction hypothesis for individual stocks in a single foreign country are limited and focus primarily on UK and other international countries ${ }^{2}$.

Clare and Thomas (1995) investigate the overreaction hypothesis in the United Kingdom (UK). Winner and loser portfolios are formed using monthly stock return data taken from the London Business School, which consist of the end-of-month dividend adjusted returns on all those stocks quoted on the London Stock Exchange. Stocks ordered into portfolios according to their performance over one, two, and three years. Their findings indicate that previous losers tend to subsequently outperform previous winners over the period 1955-1990, although the difference in performance is economically insignificant. Furthermore, losers tend to be small, and the overreaction can be explained by the firm size effect.

Dissanaike (1997), using methods employed by Chan (1988) and Ball and Kothari (1989) to control for time-varying risk, finds little evidence to support the claim that UK price reversals are due to changes in betas. Moreover, he claims that his sample restriction, using large and better-known companies, minimises the biases created by the bid-ask effect and infrequent trading, and reduces the possibility that reversals are primarily a smallfirm phenomenon.

The UK stock market is also investigated by Campell and Limmack (1997), who test for long - term reversals in the abnormal returns of UK companies classified as winners and losers over the period from January 1979 to December 1990. Their findings indicate that, in the 12 months following portfolio formation, loser companies generated positive abnormal returns. Furthermore, the smallest loser companies experienced a reversal in their abnormal returns over the following 12 months, but no such reversal existed for the smallest winner companies. Their evidence for overreaction is also supported by Patz (1989) and Capstaff et. al. (1995).

DaCosta (1994) provides evidence of overreaction in the case of Brazilian stock exchange as do Leung and Li (1998) in stocks listed on Hong Kong exchange. Gaunt (2000) supports overreaction and reversal in the Australian stock market, while Bowman and Iverson (1998) investigate the behaviour of stock prices in New Zealand after large weekly price changes. They document a stock market overreaction that is especially pronounced in the case of price declines. Moreover, the reversal is confined to the week following the overreaction and is larger the larger the initial overreaction is.

\subsection{Evidence of Stock Price Underreaction to Earnings.}

A number of other US studies suggest that market participants underreact to earnings data releases. It has been suggested that underreaction could be the result of investors' failure to recognise the importance of current earnings as an indicator of future earnings numbers. For example, evidence from Bernard and Thomas (1990) and Wiggins (1991) indicates that stock price behaviour is consistent, in part, with investors' quarterly earnings 
expectations being described by a seasonal random walk. This means that market participants under-weight recent quarterly announcements and over-weight past data (the previous year's corresponding quarterly announcement). Further evidence of US market underreaction to past earnings is provided by Mendenhall (1991) and Ali et. al. (1992).

One of the most influential studies that strongly supports analysts' aggregate tendency to underreact to prior-year earnings is Abarbanell and Bernard (A\&B) (1992). They attempt to examine the extent to which analyst' responses to earnings might explain the anomalous delayed stock price responses to earnings (Bernard and Thomas 1990), or anomalous stock price overreactions (Chopra et al., 1992). In that process, they reconcile the apparently disparate conclusions in the literature about whether analysts' forecasts underreact or overreact to earnings. They show that analysts' forecasts share some of the key properties of the naïve (seasonal random walk) earnings expectations that are consistent with the stock price behaviour documented by Bernard and Thomas (1990). However, they find no reliable evidence of an overemphasis in Value Line forecasts on the earnings of the corresponding quarter of the prior year, as occurs in a seasonal random walk. Moreover, they find that the magnitude of the autocorrelations in analysts' forecast errors are at most about half as large as necessary to explain the magnitude of the delayed stock price response to earnings. The implication is that, while the anomalous underreaction stock prices to earnings information may be partially rooted in whatever causes inefficiencies in analysts' forecasts, a full understanding of the anomaly must involve other factor as well.

They turn next to the issue of stock price overreaction, and the related question of how one can reconcile the apparent conflict between the analyst underreaction discussed above and the analyst overreaction documented by D\&T. They show that even if the "extreme" analysts' forecasts in D\&T (1990) are labelled as "overreactions", they cannot be viewed as overreactions to earnings. Moreover, they find no clear linkage between these extreme forecasts and the stock price overreactions discussed in D\&T $(1985,1987)$.

For the UK stock market, Bhaskar and Morris (1984) identified a tendency for analysts to underestimate future earnings. O'Hanlon and Whiddett (1991) carry out a similar analysis to that used by D\&T and conclude that UK analysts are prone to underreact when predict earnings forecasts. However, this conclusion is based on a relatively small sample of analysts' forecasts. Finally, Hussain (1996) generates similar conclusions with regard to UK analysts.

\section{Data and Methodology}

\subsection{Data}

Data used in this study are taken from the published monthly UK equity working lists of a major wellknown City based investment bank, covering 321 UK companies quoted on London Stock Exchange, for the period from 1989 to 2002. The market value of equity for the companies in this sample ranges from $£ 5$ million to $£ 21.5$ billion, with $\mathrm{P} / \mathrm{E}$ ratio .15 for high $\mathrm{P} / \mathrm{E}$ ratio firms (average $\mathrm{P} / \mathrm{E}$ ratio for the UK stock market equal to 15 for the sample's period) and the lower and upper quartiles, used to define large and small firms, are $£ 110$ million and £2 billion respectively (both sub-samples contain 110 firms).

Firms qualifying for inclusion in our sample were those that appeared on Datastream data files and had continuous observations of earnings forecasts for the whole sample period. Following the procedure suggested by $\mathrm{A} \& \mathrm{~B}$, earnings based variables that lie in the lower or upper $1 \%$ of the distribution were deleted from the analysis as outliers in order to mitigate the influence of extreme observations.

The lists give the earnings forecasts the day on which the information was downloaded from the in-house database and published in the equity working lists. Therefore, the earnings forecasts are more time dated than forecasts from other frequently used sources. One more advantage of this database is that actual earnings are measured on the same basis as the earnings forecasts. Analysts do not always forecast the announced earnings per share, but their adjusted version of it, since they believe that the adjusted version more accurately represents the performance of the company ${ }^{3}$. Furthermore, according to A\&B (1992), the use of consensus measures of earnings 
expectations may be problematic since their construction may induce an artificial autocorrelation in the forecast error. Finally, our sample selection may introduce some survivorship bias. However, Ball and Kothari (1989) argue that survivorship bias should have little influence on tests for stock price overreactions.

\subsection{Methodology}

We test the direction of analysts' reaction to earnings information (overreaction or underreaction) from two different views: i) the generalised overreaction and ii) the overreaction/underreaction to earnings announcement. For both models, we run six regressions for different forecast horizons $(1,2,3,6,12$ months intervals and all horizons for the full-sample) in order to test for greater overreaction as the uncertainty increases ${ }^{4}$. In our testing procedure, we separate the sample's firms into two groups, according to their size (large and small), and also make a distinction between high and low P/E ratio firms in order to investigate whether analysts' reaction to earnings is particularly related to firm size and growth opportunities respectively.

More specifically, the first testing hypothesis (H1) is that of overreaction in analysts' forecasts, without take in account the level of the price/earning ratio. In order to test (H1) we employ the following D\&T (1990) regression of actual earnings changes against forecasted changes:

$\mathbf{E t}-\mathbf{E t}-1=\alpha+\delta(\mathbf{F t}-\mathbf{E t}-1)+\varepsilon t$

where:

$(E t-E t-1)=$ the actual changes in earnings per share (EPS);

$(\mathrm{Ft}-\mathrm{Et}-1)=$ the forecasted changes in EPS;

$\alpha, \delta=$ model parameters;

$\varepsilon \mathrm{t}=$ a zero mean error term.

The standard definition of a rational forecast Ft would require that $\alpha$ equal to zero and $\delta$ equals to one. In contrast, a non-zero estimate of $\alpha$ indicates bias in the forecast. The estimate of the slope, which is interpreted as the coefficient of forecasting ability for analyst, is the focus of our immediate concern. We test for overreaction according to $\delta$. If forecasted changes in EPS are too extreme then $\delta$ will be less than one.

Furthermore, we test hypothesis 1a (H1a) of overreaction in analysts' forecasts, with take in account the level of the price/earning ratio. In eq. 1 we include a dummy variable which takes the value of (Ft $-\mathrm{Et}-1)$ for high $\mathrm{P} / \mathrm{E}$ ratio companies and zero for the low $\mathrm{P} / \mathrm{E}$ ratio companies. By doing this, we can test whether analysts overreact differently in the case of companies with high growth opportunities (high $\mathrm{P} / \mathrm{E}$ ratio), for which uncertainty is more severe. Specifically, we estimate the following equation:

$\mathbf{E t}-\mathbf{E t}-\mathbf{1}=\alpha+\delta(\mathbf{F t}-\mathbf{E t}-\mathbf{1})+\gamma \mathbf{D}+\mathbf{\varepsilon t}$

In the above equation, $\delta$ and the sum of $\delta$ and $\gamma$ show whether analysts overreact or underreact for low and high P/E ratio companies respectively. If $\delta$ and $\delta$ than one then analysts overreact for both low and high P/E ratio companies.

The second hypothesis (H2) we test is that of whether overly extreme earnings forecasts are best characterised in terms of overreaction or underreaction to prior earnings. In order to test (H2) we employ the following $\mathrm{A} \& \mathrm{~B}$ (1992) regression of forecast error in a given year against the actual earnings change for the prior year: 
$\mathbf{E t}-\mathbf{F t}=\alpha+\beta(\mathbf{E t}-1-\mathbf{E t}-2)+\mathbf{\varepsilon t}$

$\mathrm{Et}=$ annual EPS for year $\mathrm{t}$;

$\mathrm{Ft}=$ analysts' forecast of annual EPS for year $\mathrm{t}$;

$\alpha, \beta=$ model parameters;

$(\mathrm{Et}-\mathrm{Ft})=$ the forecast error;

$($ Et-1 - Et-2) $=$ the prior years earnings changes;

$\varepsilon \mathrm{t}=$ disturbance term.

If $\mathrm{Ft}$ is an efficient forecast, then $\beta$ would be zero. An estimate greater than (less than) zero is indicative of underreaction (overreaction) to prior year's earnings changes. The key implication in equation (3) is that $\beta$ can be positive, indicating underreaction, even while $\delta$ in equation (1) is less than one, indicating that forecasted changes tend to be too extreme.

Furthermore, we test hypothesis 2a (H2a) of whether overly extreme earnings forecasts are best characterised in terms of overreaction or underreaction, with take in account the level of the price/earning ratio. In other words, we make a distinction between high and low P/E using the previous model (equation 3), but we need to add a dummy variable. Specifically, we estimate the following equation:

$\mathbf{E t}-\mathbf{F t}=\alpha+\beta(\mathbf{E t}-1-\mathbf{E t}-2)+\gamma \mathbf{D}+\varepsilon \mathbf{t}$

Equation (4) has the same explanation as equation (3) plus the extra dummy variable D and coefficient $\gamma$. D becomes (Et-1 - Et-2) for the high P/E ratio firms and zero for the low P/E ratio firms. An estimate of $\beta$ greater than (less than) zero is indicative of underreaction (overreaction) to prior year's earnings changes for low P/E ratio companies. Also, if $\gamma$ is greater than zero this indicates that analyst's underreaction is higher for high P/E ratio firms.

\section{Empirical Results}

\subsection{Generalised Overreaction}

Table 1 and 2 report the results of the Ordinary Least Square (OLS) regression analysis based on D\&T model (eq. 1 and 2$)^{5}$. $\mathrm{R}^{2}$ is relative high for the majority of the regressions. However, we find heteroscedasticity in six of regressions (for 1,3,12, month's horizons with and without dummy). We use the White (1980) correction for heteroskedasticity to account for this problem ${ }^{6}$. Table 1 presents our estimates of $\alpha$ and $\delta$ along with their t-statistics and $\mathrm{R} 2$ at all monthly forecast horizons and for the full-sample using eq. 1.

Table 1

Analysts' overreaction to actual earnings per share changes

Et- Et-1 $=\alpha+\delta(\mathbf{F t}-\mathbf{E t}-1)+\boldsymbol{\varepsilon} \mathbf{t}$

\begin{tabular}{lccccc}
\hline $\begin{array}{l}\text { Monthly } \\
\begin{array}{l}\text { Forecast } \\
\text { Horizon }\end{array}\end{array}$ & $\alpha$ & $\begin{array}{c}\mathrm{t} \text {-statistic } \\
\text { for Test of } \\
\alpha=0\end{array}$ & $\delta$ & $\begin{array}{c}\text { t-statistic } \\
\text { for } \\
\text { Test of } \delta=1\end{array}$ & $\mathrm{R}^{2}$ \\
\hline 1 & -59.21 & $(-1.59)$ & 0.34 & $(-2.5)^{*}$ & 0.34 \\
2 & -6.5 & $-5.35 *$ & 1.2 & $2.7 *$ & 0.59 \\
3 & -11.64 & $(-5.87)^{*}$ & 1.07 & $(0.2)$ & 0.46 \\
6 & -9.2 & $-4.2 *$ & -0.001 & $-4.11^{*}$ & 0.14 \\
12 & -59.91 & $(-1.8)$ & 0.33 & $(-2.5)^{*}$ & 0.33 \\
All horizons & -6.3 & $-7 *$ & 0.02 & $-8.07 *$ & 0.61 \\
(full sample) & & & & & \\
\hline
\end{tabular}

* indicates that the intercept and the slope are significantly different from zero and one respecttively at 0.05 level. ( ) indicates t- stats using White standard error. 
The $\alpha$ estimate is -6.3 with $\mathrm{t}=-7$ and $\mathrm{R}^{2}=0.62$ for the full-sample. The sign of the intercept at the other monthly horizons is also negative, while it is significant (at 0.05 level) in almost all the cases. The negative intercept indicates that projected earnings exceed actual earnings. These results are consistent with D\&T findings, indicating overly optimistic analysts.

The results for $\delta$ coefficient support the generalised overreaction hypothesis. In four out of six regressions, $\delta$ is significantly less than one. This size of the slope coefficient indicates that actual earnings change by less than the change in analysts' forecasts.

On the other hand, in the regressions for the second and third month's forecast horizon we observe that $\delta$ coefficient is greater than one, suggesting underreaction. However, $\delta$ is statistically different than one only in one case ( 2 month's forecast horizon). Finally, our findings do not support the hypothesis of increased overreaction as the forecast horizon increases in contrast to D\&T (1990) findings.

In the regressions with the dummy, $\delta$ shows the overreaction or underreaction of analysts for the low $\mathrm{P} / \mathrm{E}$ ratio companies, while the sum of $\gamma$ and $\delta$ shows the same for high P/E ratio companies. From the results of Table 2, $\gamma$ is positive at almost all monthly forecast horizons, suggesting that analysts overreact less in the cases of high P/E ratio companies. Moreover, we find that analysts overreact in the low $\mathrm{P} / \mathrm{E}$ ratio firms and underreact in the high $\mathrm{P} / \mathrm{E}$ ratio ones $(\delta<1, \gamma$ and $\gamma+\delta>1)$ in the regression for the full-sample.

Table 2

Analysts' overreaction to actual earnings per share changes with Dummy Et $-\mathbf{E t}-1=\alpha+\delta(\mathbf{F t}-\mathbf{E t}-1)+\gamma \mathbf{D}+\boldsymbol{\varepsilon} \mathbf{t}$

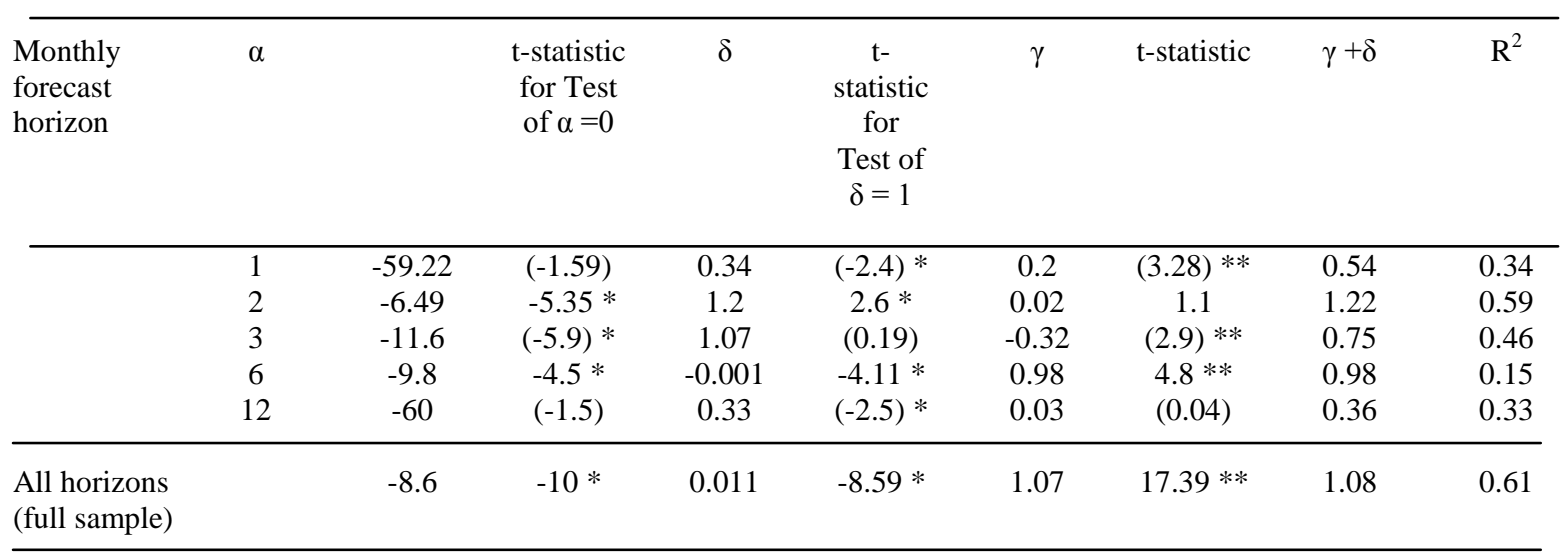

* indicates that the intercept and the slope are significantly different from zero and one respectively at 0.05 level.

** indicates statistically significant $\gamma$ coefficient at 0.05 level.

( ) indicates t- stats using White standard error.

This finding contradicts the earlier argument in the literature of market anomalies, that low P/E stocks will outperform high $\mathrm{P} / \mathrm{E}$ stocks because growth companies enjoy high $\mathrm{P} / \mathrm{E}$ ratios, but the market tends to overestimate the growth potential and thus overvalues these growth companies, while undervaluing low-growth firms with low P/E ratios (e.g., Basu, 1977). 3.

The estimates of $\delta$ and their significance from the analysis of the impact of firm size are presented in Table 
Table 3

Analysts' overreaction to actual earnings per share changes for large and small firms

\begin{tabular}{ccccc} 
& \multicolumn{2}{c}{ Large firms } & \multicolumn{2}{c}{ Small firms } \\
\hline $\begin{array}{c}\text { Monthly } \\
\text { Forecast } \\
\text { Horizon }\end{array}$ & $\delta$ & $\begin{array}{c}\text { t-statistic for } \\
\text { Test of } \delta=1\end{array}$ & $\delta$ & $\begin{array}{c}\text { t-statistic } \\
\text { for } \\
\text { Test of } \delta=1\end{array}$ \\
\hline 1 & 0.67 & $(-0.068)$ & 0.19 & -0.06 \\
2 & 0.23 & $3.67^{*}$ & -0.01 & $(0.03)$ \\
3 & 0.09 & 0.061 & 0.07 & 0.02 \\
6 & 0.06 & $(4.98)^{*}$ & 0.02 & $(-0.085)$ \\
12 & 0.13 & $2.78^{*}$ & 0.08 & $(-0.05)$ \\
\hline All horizons & 0.47 & $(6.31)^{*}$ & 0.03 & -0.07 \\
(full sample) & & & & \\
\hline
\end{tabular}

* indicates that the slope estimates are significantly different from one at 0.05 level.

( ) indicates t- stats using White standard error.

The slope coefficients for small firms are less than one but not significant at a 0.05 level at any horizon, indicating no significant overreaction to earnings. This finding is inconsistent to the firm size effect supported by Clare and Thomas (1995) for the UK stock market. For large firms the results are different. The slope estimates are insignificantly less than one at the 1 and 3 month forecast horizon, but become significant at the other horizons, supporting the generalized overreaction. However, these findings do not support the hypothesis for increased overreaction regarding the forecast horizon.

\subsection{Over/under-reaction in Earnings Announcements}

Tables 4 and 5 report the results of the OLS regressions when we adopt A\&B model (eq. 3 and 4). The $\mathrm{R}^{2}$ of these regressions are very low as in the case of A\&B findings. Also, in these regressions we do not face heteroscedasticity problems.

Our findings from Table 4 do not support the underreaction hypothesis suggested by A\&B (1992). The sign of the intercepts still remain negative. However, $\beta$ coefficient is negative but very close to zero at all monthly forecast horizons and for the full-sample.

Insert Table 4

Only in one case $\beta$ is statistically negative ( 2 month's forecast horizon). On the contrary to the previous evidence for generalised overreaction, these estimates for $\beta$ suggest that analysts are efficient regarding their reaction in the earnings announcements.

In the regressions with the dummy, we find similar results. The results from Table 5 show that the $\beta$ coefficient and the sum of $\gamma$ and $\beta$ are always close to zero. Only in the case of 6 month's forecast horizon the slope and the $\gamma$ coefficient are significantly different than zero.

On the contrary to the previous case of generalized overreaction, our estimates do not support that analysts react differently regarding high and low $\mathrm{P} / \mathrm{E}$ ratio companies at almost all forecast horizons. Overall, the results show that analysts are efficient regarding their forecasts for both high and low P/E ratio companies. 
Table 4

Analysts' Underreaction/Overreaction to prior Earnings Changes

Et-Ft $=\alpha+\beta($ Et-1- Et-2) $+\varepsilon \mathbf{t}$

\begin{tabular}{cccccc}
\hline $\begin{array}{c}\text { Monthly } \\
\text { forecast } \\
\text { Horizon }\end{array}$ & $\alpha$ & $\begin{array}{c}\text { t-statistic } \\
\text { for Test of } \\
\alpha=0\end{array}$ & $\beta$ & $\begin{array}{c}\text { t-statistic for } \\
\text { Test of } \beta=0\end{array}$ & $\mathrm{R}^{2}$ \\
\hline 1 & -86.8 & -1.57 & -0.002 & -0.05 & 0.001 \\
2 & -5.1 & $-4.03^{*}$ & -0.15 & $2.8^{*}$ & 0.039 \\
3 & -11.6 & $-6.3^{*}$ & -0.001 & -0.7 & 0.002 \\
6 & -87.2 & -1.5 & -0.002 & -0.04 & 0.003 \\
12 & -89.5 & -1.52 & -0.002 & -0.04 & 0.001 \\
\hline All horizons & -65.07 & $4.2^{*}$ & -0.004 & -0.19 & 0.004 \\
(full sample) & & & & & \\
\hline
\end{tabular}

* indicates that the intercept and the slope are significantly different from zero at 0.05 level.

Table 5

Analysts' Underreaction/Overreaction to prior Earnings Changes with Dummy

Et-Ft $=\alpha+\beta($ Et-1- Et-2) $+\gamma$ D+ $\varepsilon$ t

\begin{tabular}{|c|c|c|c|c|c|c|c|c|}
\hline $\begin{array}{l}\text { Monthly } \\
\text { forecast } \\
\text { Horizon }\end{array}$ & $\alpha$ & $\begin{array}{l}\text { t-statistic } \\
\text { for Test } \\
\text { of á }=0\end{array}$ & $\beta$ & $\begin{array}{c}\text { t-statistic } \\
\text { for Test } \\
\text { of } \beta=0\end{array}$ & $\gamma$ & t-statistic & $\gamma+\beta$ & $R^{2}$ \\
\hline $\begin{array}{c}1 \\
2 \\
3 \\
6 \\
12\end{array}$ & $\begin{array}{l}-87.7 \\
-4.7 \\
-8.7 \\
-31 \\
-90.5\end{array}$ & $\begin{array}{c}-1.57 \\
-3.33^{*} \\
-5.3^{*} \\
-0.5 \\
-1.5\end{array}$ & $\begin{array}{c}-0.008 \\
0.18 \\
0.001 \\
8.75 \\
-0.008\end{array}$ & $\begin{array}{l}-0.13 \\
2.3 \\
-0.4 \\
2.4^{*} \\
-0.11\end{array}$ & $\begin{array}{l}0.02 \\
-0.07 \\
-0.54 \\
-9.2 \\
0.02\end{array}$ & $\begin{array}{c}0.15 \\
-0.56 \\
-0.8 \\
2.4^{* *} \\
0.12\end{array}$ & $\begin{array}{c}0.01 \\
0.11 \\
-0.54 \\
-0.4 \\
0.008\end{array}$ & $\begin{array}{c}0.002 \\
0.041 \\
0.025 \\
0.023 \\
0.09\end{array}$ \\
\hline $\begin{array}{l}\text { All horizons } \\
\text { (full sample) }\end{array}$ & -64.3 & $-4.1^{*}$ & 0.001 & -0.22 & -0.13 & -0.23 & -0.13 & 0.003 \\
\hline
\end{tabular}

* indicates that the intercept and the slope are significantly different from zero at 0.05 level.

** indicates statistically significant $\gamma$ coefficient at 0.05 level.

Table 6 presents the estimates of $\beta$ from the investigation of the direction of analysts' reaction between large and small- size firms.

The slope estimates for small firms are still less than zero but not significant at 0.05 level at all horizons. However, for large firms the results are somewhat mixed. $\beta$ coefficient is significantly less than zero at 1,3 and 12 months horizon, indicating overreaction to prior earnings announcements. However, this is not the case for the rest forecast horizons, where estimates are insignificant.

\section{Concluding Remarks}

In this paper we provide further evidence of analysts' reaction to earnings information in the UK stock market over the period 1989-2002. More specifically, we test two forms of overreaction (generalized overreaction and overreaction to prior earnings) in relation to three aspects of analysts' information environment (forecast horizons, firm size and $\mathrm{P} / \mathrm{E}$ ratio). 
Table 6

Analysts' overreaction to actual earnings per share changes for large and small firms

\begin{tabular}{ccccc}
\hline \multicolumn{2}{c}{ Large firms } & & \multicolumn{2}{c}{ Small firms } \\
$\begin{array}{c}\text { Monthly forecast } \\
\text { Horizon }\end{array}$ & $\beta$ & $\begin{array}{c}\text { t-statistic for } \\
\text { Test of } \beta=0\end{array}$ & $\beta$ & $\begin{array}{c}\text { t-statistic for } \\
\text { Test of } \beta=0\end{array}$ \\
\hline 1 & -0.27 & $-3.44^{*}$ & -0.003 & $(0.048)$ \\
2 & -0.001 & 0.009 & -0.0025 & $(-0.29)$ \\
3 & -0.09 & $(6.78)^{*}$ & -0.09 & $(0.26)$ \\
6 & -0.003 & -0.017 & -0.0037 & -0.11 \\
12 & -0.53 & $3.62 *$ & -0.01 & $(-0.05)$ \\
\hline All horizons & -0.012 & -0.038 & -0.067 & -0.03 \\
(full sample) & & & & \\
\hline
\end{tabular}

${ }^{*}$ indicates that the slope estimates are significantly different from zero at 0.05 level.

( ) indicates t- stats using White standard error.

Our results provide evidence for generalised overreaction. We find that analysts are overoptimistic and that on average overreact to information, the source of which is unknown. On the contrary, our estimates do not support the underreaction hypothesis to earnings announcements. This evidence suggests that analysts are efficient on their forecasts based on the earnings announcements. Furthermore, the results based on both models do not support the overreaction due to small firm effect, the prior expectation about the overreaction for high price/earning ratio companies and the higher overreaction regarding the forecasting horizon.

There are two potential reasons, which may explain our results, regarding the overreaction of analysts. First, there may be "institutional reasons" that trigger the reported overreaction. Analysts employed in brokerage firms probably report overoptimistic forecasts, in order to make their customers to increase the volume of trade, and as a result to increase brokerage firm's profitability.

The second reason is related to private information. Some of the listed companies employ analysts who trade their stocks on their behalf. These analysts are considered to have private information. Also, Daniel et. al. (1998) find that investors who have private information overreact to it. As a result, the reported overreaction may be due to the private information that analysts collect. However, if we assume that analysts base their estimation on the Miller and Modigliani (1961) model, in which the stock price of a company is calculated by the short-term earnings and the growth opportunities, the private information argument is invalidated.

According to Miller and Modigliani model, analysts may overreact to earnings announcement or to information related to growth opportunities. Our findings, however, suggest that analysts do not systematically overreact to earnings announcements and that analysts are efficient regarding this source of information. Also, we find that analysts do not overreact or less underreact regarding their forecasts for firms with growth opportunities (high P/E ratio). As a result, we cannot argue that the reported overreaction is due neither to private information of short-term earnings, nor to the information for the future perspectives of the companies. We believe that our findings are more likely to be explained by the institutional argument.

Finally, our evidence for generalized overreaction comes to support the overreaction hypothesis reported from earlier UK studies (e.g., Patz, 1989; Capstaff et. al. 1995; Campell and Limmack, 1997), while it is inconsistent to other relevant studies (e.g., Bhaskar and Morris, 1984; O'Hanlon and Whiddett, 1991; Hussain, 1996), during 1980s and mid '90s. However, based on our overreaction evidence for only large firms at some monthly forecast horizons, we have to mention that the contradictory findings in the UK literature during the last three decades may be a product of the size distribution of firms included in the various samples used by prior 
researchers. Overall, according to Kothari's (2001) overview for the overreaction research, the debate concerning both the existence and cause of this phenomenon still continues.

\section{Footnotes}

1. In a review article which is heavily critical of much of overreaction literature, Fama (1998) claims that many of these studies' results are due to methodological problems, rejecting the suggestion that the evidence is consistent with a general tendency of markets to overreact and its interpretation as a manifestation of investors' irrational behaviour.

2. Other studies that use non-US data investigate the overreaction hypothesis in amulti-country setting using national stock market indexes. Most of them provide evidence of overreaction (e.g., Richards, 1997; Baytas and Cakici, 1999), while others either report both reactions, depending on the size of the market's speculative bubble, the economic growth of the particular market and the exchange rate volatility of the local currency (e.g., Schnusenberg and Madura, 2001) or reject the overreaction hypothesis (e.g., Lasfer et. al., 2003).

3. It could be argued that forecasts from analysts employed by a single investment bank are not representative of market forecasts. However, Stickel (1990) argues that analysts following a particular firm exhibit a herd instinct when revising forecasts so it is unlikely that one analyst's forecast will deviate significantly from the consensus. O'Brien (1990) do not find systematic differences in forecast accuracy across individuals, while O'Brien (1988) argues that the most recent forecasts of individual analysts can prove superior to the use of consensus forecasts, like those available on the Institutional Brokers Estimate System (IBES), which may include old or stale data.

4. The forecast horizons studied here are of particular interest because many UK firms give interim data instead of quarterly announcements, but also because analysts usually appear to be more concerned with revising their forecasts at shorter horizons. According to Cooper and Taylor (1983), UK analysts' forecasts post-interim appear to be significantly superior to those generated pre-interim.

5. Analysis of the data indicated that there was a problem of normality. This problem is overcome by including stationary dummy variables. However, exclusion of the dummies does not alter the pattern of results.

6. The interpretation of the following results using both D\&T and A\&B methodologies remains almost similar, even when we apply estimation based upon Seemingly Unrelated Regression Equations (SURE), which accounts for heteroskedasticity and contemporaneous correlation in the errors. In the interests of brevity, SURE estimates are not presented here. Results are available from the authors on request.

\section{References}

1. Abarbanell, J. S. and Bernard, V. L. (1992) 'Tests of analysts' overreaction or underreaction to earnings information as an explanation for anomalous stock price behaviour', Journal of Finance, 47: 1181-207.

2. Albert, R. L. and Henderson, G. V. (1995) 'Firm size, overreaction and return reversals', Quarterly Journal of Business and Economics, 34(4): 60-80.

3. Ali, A., Klein, A. and Rosenfeld, J. (1992) 'Analysts' use of information about permanent and transitory earnings components in forecasting annual EPS', Accounting Review, 67: 183-98.

4. Ball, R. and Kothari, S. P. (1989) 'Nonstationary expected returns: implications for tests of market efficiency and serial correlation in returns', Journal of Financial Economics, 25: 51-74.

5. Basu, S. (1977) 'Investment performance of common stocks in relation to their price-earnings ratios: a test of the efficient market hypothesis', Journal of Finance, 12: 663-82.

6. Baytas, A. and Cakici, N. (1999) 'Do markets overreact: international evidence', Journal of Banking and Finance, 23: 1121-44.

7. Bernard, V. L. and Thomas, J. K. (1990) 'Stock prices and earnings implications', Journal of Accounting and Economics, 13: 305-340.

8. Bhaskar, K. N. and Morris, R. C. (1984) 'The accuracy of brokers' profit forecasts in the UK', Accounting and Business Research, Spring: 113-24.

9. Bowman, R. G. and Iverson, S. D. (1998) 'Short-run overreaction in the New Zealand stock market', Pacific-Basin Finance Journal, 6: 475-91.

10. Campell, K. and Limmack, R. J. (1997) 'Long-term overreaction in the UK stock market and size adjustment', Applied Financial Economics, 7: 537-48.

11. Capstaff, J., Paudyal, K. and Rees, W. (1995) 'The accuracy and rationality of earnings forecasts by UK analysts', Journal of Business Finance and Accounting, 22(1): 69-87.

12. Chan, K. C. (1988) 'On the contrarian investment strategy', Journal of Business, 61: 147-63.

13. Chopra, N., Lakonishok, J. and Ritter, J. R. (1992) 'Measuring abnormal performance: do stock markets overreact?' Journal of Financial Economics, 31(2): 235-68. 
14. Clare, A. and Thomas, S. (1995) 'The overreaction hypothesis and the UK stock market', Journal of Business Finance and Accounting, 22: 961-73.

15. Conrad, J. and G. Kaul (1993) 'Long term market overreaction or bias in computed returns?', Journal of Finance, 48: 39-63.

16. Cooper, T. and Taylor, B. (1983) 'How good are stockbrokers' earnings forecasts?', The Investment Analyst, January: 14-23.

17. DaCosta, N. C. A. (1994) 'Overreaction in the Brazilian stock market', Journal of Banking and Finance, 18: 633-42.

18. Daniel, K., Hirshleifer, D. and Subrahmanyam, A. (1998) 'Investor psychology and security market under- and overreactions', Journal of Finance, 53: 1839-85.

19. Debondt, W. F. M. and. Thaler, R. H. (1985) 'Does the stock market overreact?', Journal of Finance, 40: 793-805.

20. DeBondt, W. F. M. and Thaler, R. H. (1987) 'Further evidence of investor overreaction and stock market seasonality', Journal of Finance, 42: 557-82.

21. DeBondt, W. F. M. and Thaler, R. H. (1990) 'Do security analysts overreact?', American Economic Review, 52: 1-21.

22. Dissanaike, G. (1997) 'Do stock market investors overreact?', Journal of Business Finance and Accounting, $24: 27-49$.

23. Fama, E. (1998) 'Market efficiency, long-term returns, and behavioral finance', Journal of Business, 73(2): 161-75.

24. Hussain, S. (1996), "Over-reaction by security market analysts: the impact of broker status and firm Size", Journal of Business Finance and Accounting, December: 1223-44.

25. Kaul, G. and Nimalendran, M. (1990), 'Price reversal: bid-ask errors or market overreaction?', Journal of Financial Economics, 28: 67-93.

26. Kothari, S. (2001), 'Capital markets research in accounting', Journal of Accounting and Finance, 31: $105-231$.

27. Lasfer, M. A., Melnik, A. and Thomas, D. C. (2003) 'Short-term reaction of stock markets in stressful circumstances', Journal of Banking and Finance, 27: 1959-77.

28. Leung, R. W. T. and Li, M. (1998) 'Does the Hong Kong stock market overreact?', Asian Review of Accounting, 6(2): 101-16.

29. Loughran, T. and Ritter, J. R. (1996) 'Long-term market overreaction: the effect of low-priced stocks', Journal of Finance, 51: 1959-70.

30. Miller, M. H. and Modigliani, F. (1961) 'Dividend policy, growth and the valuation of shares', Journal of Business, 34: 411-33.

31. O'Brien, P. C. (1988) 'Analysts' forecasts as earnings expectations', Journal of Accounting and Economics, 10: 53-88.

32. O'Brien, P. C. (1990) 'Forecast accuracy of individual analysts on nine industries', Journal of Accounting Research, 28(2): 286-304.

33. O'Hanlon, J. and Whiddett, R. (1991) 'Do UK security analysts overreact?', Accounting and Business Research, Autumn: 63-74.

34. Patz, D. H. (1989) 'UK analysts' earnings forecasts', Accounting and Business Research, Summer: 267-75.

35. Richards, A. J. (1997) 'Winners-loser reversal in national stock market indices: can they be explained?', Journal of Finance, 52: 2129-44.

36. Schnusenberg, O. and Madura, J. (2001) 'Global and relative over- and underreaction in international stock market indexes', Mimeo, St. Joseph's University, Philadelphia.

37. Stickel, S. E. (1990) 'Predicting individual analyst earnings forecasts', Journal of Accounting Research, Autumn: 40917.

38. White, H. (1980) 'A heteroskedastic-consistent covariance matrix estimator and a direct test for heteroskedasticity', Econometrica, May: 817-28.

39. Wiggins, J. B. (1991) 'Do misperceptions about the earnings process contribute to post announcement drift?', Working paper, Cornell University.

40. Zarowin, P. (1990) 'Size, seasonality and stock market overreaction', Journal of Financial and Quantitative Analysis, 25(1): 113-25. 